Original Research Article

\title{
Prescription pattern of antimicrobials in pregnant women attending antenatal clinic in a tertiary care hospital in Telangana, India
}

\author{
Md. Amirunnisa Begum*, B. Krishna Sowmya, D. Shailendra
}

Department of Pharmacology, Mediciti Institute of Medical Sciences, Ghanpur, Medchal Telangana, India

Received: 14 November 2018 Accepted: 28 December 2018

*Correspondence to: Dr. Md. Amirunnisa Begum, Email: mohammadamirunnisa@ gmail.com

Copyright: (C) the author(s), publisher and licensee Medip Academy. This is an openaccess article distributed under the terms of the Creative Commons Attribution NonCommercial License, which permits unrestricted noncommercial use, distribution, and reproduction in any medium, provided the original work is properly cited.

\begin{abstract}
Background: Pregnancy is a physiological condition during which immune system is weakened. Therefore, most women are prone to develop infections during this period for which antimicrobials are prescribed. Drugs used during pregnancy may lead to teratogenicity. Therefore, this study was done with the following objectives: 1.to determine the type of infections encountered, 2.to assess the prescription profile of antimicrobials and 3.to assess FDA categories of antimicrobials used in pregnant women in a tertiary care center in Telangana, India.

Methods: This was a prospective observational study conducted on pregnant women attending antenatal clinic (ANC) at Mediciti Institute of Medical Sciences (MIMS) from 1st January 2018 to 30th June 2018.

Results: Out of a total of 165 cases enrolled, 57 (34.5\%) cases were prescribed antimicrobials and $108(65.5 \%)$ were treated symptomatically. The mean (SD) age of women who were prescribed antimicrobials was 22.9 (2.97) years. Of the conditions encountered, respiratory tract infections (RTIs) accounted for $31 \%$, followed by urinary tract infections (UTIs) $26 \%$ and gastroenteritis $25 \%$. Most prevalent infections which required antimicrobials prescription were UTIs $(36.84 \%)$, followed by Gastroenteritis $(17.54 \%)$. Majority of the antimicrobials prescribed were from Betalactams $(40.34 \%)$, followed by Nitrofuranes $(29.82 \%)$, Nitroimidazoles $(17.54 \%)$ and Antifungals $(8.77 \%)$. Antimicrobials prescription was more in the 3 rd trimester $(63.1 \%)$, followed by $2^{\text {nd }}$ trimester $(31.6 \%)$ and $1^{\text {st }}$ trimester $(5.3 \%)$. Majority of the antimicrobials were administered orally $(75.44 \%)$, followed by injections $(15.79 \%)$ and per vaginal route $(8.77 \%)$. Antimicrobials were mostly prescribed from FDA Category B (96\%).

Conclusions: RTIs were the most common among the conditions encountered. However, UTIs were the leading cause for antimicrobial prescriptions. Antimicrobials prescription was more during $3^{\text {rd }}$ trimester. Most antimicrobials prescribed were safe as they were from FDA Category B.
\end{abstract}

Keywords: Antimicrobials, FDA category, Infections, Pregnancy

\section{INTRODUCTION}

Pregnancy is a physiological condition during which immune system is weakened. ${ }^{1}$ Most women are prone to develop respiratory tract infections (RTIs), urinary tract infections (UTIs) and ear, nose, and throat infections during pregnancy. ${ }^{2,3}$ Antimicrobials are the most common among the prescribed drugs during this period to combat the acquired infections. ${ }^{4-6}$

Drugs used during pregnancy may lead to teratogenicity. 7,8 In 1979, the United States Food and Drug Administration (FDA) introduced a system of rating pregnancy-risk associated with pharmacological agents. This system 
categorised all drugs approved after 1983 into one of five pregnancy risk categories (A, B, C, D, and X). It indicates the effect of the agent on the fetus based on available animal and human data and recommends the degree of precaution that should be undertaken with each drug. ${ }^{1}$

Despite inadequate studies on the safety and effectiveness of prescription drugs for pregnant women, physicians prescribe surprisingly a large number of drugs. ${ }^{9}$ There are not many clinical studies available on the antimicrobials prescription during pregnancy.

Therefore, this study was conducted in pregnant women attending antenatal clinic (ANC) in a tertiary care hospital in Telangana, India with the following objectives:

- To determine the type of infections encountered

- To assess the prescription profile of antimicrobials used and

- To assess FDA categories of antimicrobials used.

\section{METHODS}

This was a prospective observational study conducted on pregnant women who attended antenatal clinic (ANC) at Mediciti Institute of Medical Sciences (MIMS) from $1^{\text {st }}$ January 2018 to $30^{\text {th }}$ June 2018 .

Ethics committee clearance was obtained from the Institutional ethics committee.

\section{Inclusion criteria}

Pregnant women who were either prescribed antibiotics or given symptomatic treatment for the similar conditions were enrolled after taking informed consent.

\section{Exclusion criteria}

Pregnant women diagnosed with acute and chronic medical conditions requiring hospitalization were excluded from the study.

The data was collected as per the proforma which comprised of participant details such as age, obstetric formula, parity and gestational age.

Data analysis sheet also contained the following information: chief complaints, investigations done (Hemoglobin, Complete Urine Examination and Random blood sugar), co-morbid conditions, provisional diagnosis, antimicrobial(s) prescribed and their dose, duration, route of administration and FDA category. The results were calculated using Quick Statistics Calculators. ${ }^{10}$

\section{RESULTS}

A total of 165 cases were enrolled, of which 57 (34.5\%) were prescribed antimicrobials and 108 (65.5\%) were treated symptomatically (Table 1 ).
The mean (SD) age among those prescribed antimicrobials was 22.9 (2.97) years and those received symptomatic treatment was 24.1 (3.68) years. No significant difference was noticed in the prescription of antimicrobials by gravidity $(\mathrm{P}=0.85)$ and parity $(\mathrm{P}=0.19)$.

Table 1: Conditions encountered - modes of treatment.

\begin{tabular}{|llll|}
\hline Diagnosis & $\begin{array}{l}\text { Anti- } \\
\text { microbial }\end{array}$ & Symptomatic & Total \\
\hline UTI & 21 & 22 & 43 \\
\hline Gastroenteritis & 10 & 32 & 42 \\
\hline Pyrexia & 08 & 00 & 08 \\
\hline RTI & 04 & 47 & 51 \\
\hline Candidiasis & 05 & 00 & 05 \\
\hline $\begin{array}{l}\text { Cervical } \\
\text { circlage }\end{array}$ & 03 & 00 & 03 \\
\hline Others & 06 & 07 & 13 \\
\hline & $57(34.5 \%)$ & $108(65.55 \%)$ & 165 \\
\hline
\end{tabular}

Of the conditions encountered, RTIs accounted for $31 \%$, followed by UTIs (26\%), Gastroenteritis (25\%), Pyrexia $(5 \%)$, Candidiasis (3\%), Cervical circlage (2\%) and others $(8 \%)$ (Threatened preterm, Viral pneumonia and Road traffic accidents) (Figure 1).

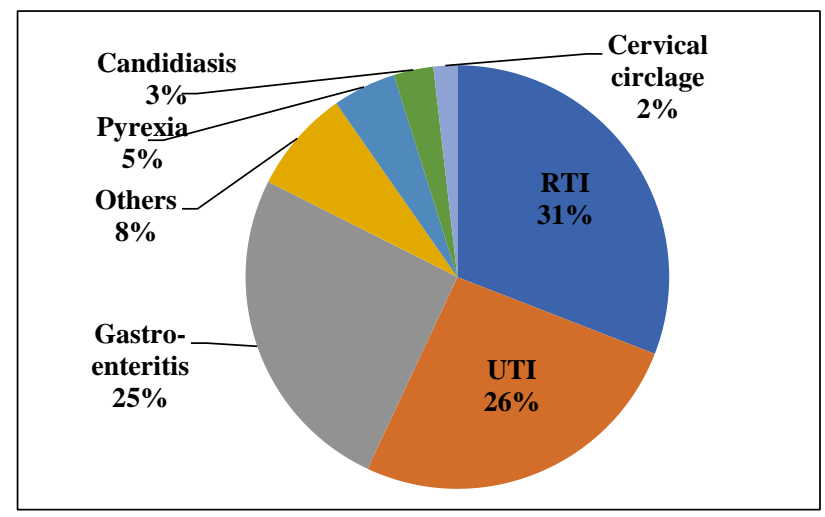

Figure 1: Frequency of conditions encountered at ANC.

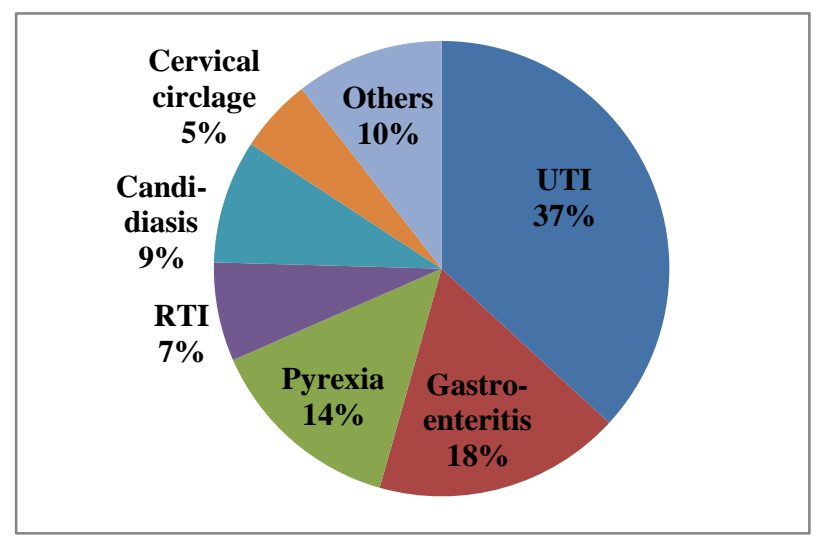

Figure 2: Percentage prescription of antimicrobials for various conditions. 
Most prevalent infections which required antimicrobials prescription were UTIs $(36.84 \%)$, followed by Gastroenteritis (17.54\%), Pyrexia (14.03\%), Candidiasis $(8.77 \%)$, RTIs $(7.01 \%)$, Cervical circlage $(5.26 \%)$ and others $(10.52 \%)$ (Figure 2).

Majority of the antimicrobials prescribed were from Betalactams (40.34\%), followed by Nitrofuranes (29.82\%), Nitroimidazoles (17.54\%), Antifungals (8.77\%) and Others (3\%) (Figure 3).

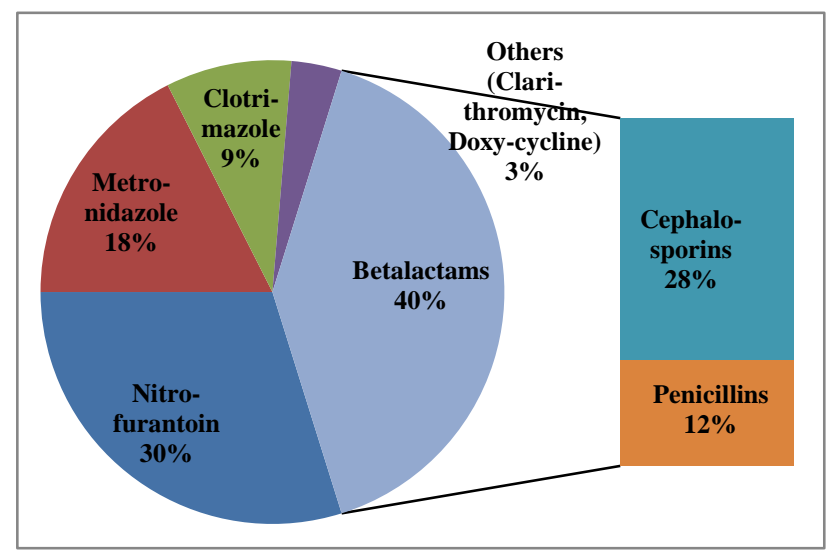

Figure 3: Percentage of antimicrobials prescribed.

Antimicrobials prescription was more in the $3^{\text {rd }}$ trimester $(63.1 \%)$, followed by $2^{\text {nd }}$ trimester $(31.6 \%)$ and $1^{\text {st }}$ trimester $(5.3 \%)$ (Figure 4$)$.

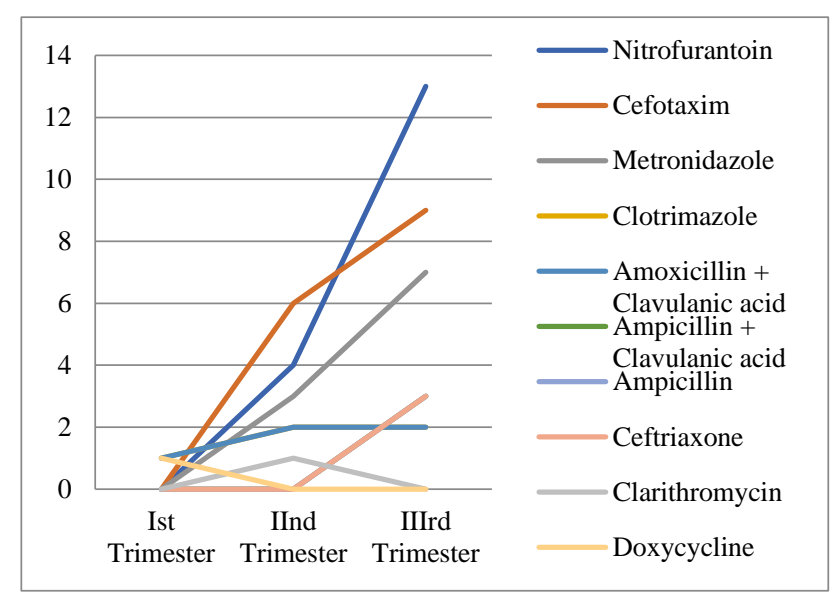

Figure 4: Antibiotic use and trimester of exposure.

Most commonly prescribed drugs were: Nitrofurantoin for UTIs, Cefotaxime for RTIs and pyrexia; and Metronidazole for Gastroenteritis.

Majority of the antimicrobials were administered orally $(75.44 \%)$, followed by injections $(15.79 \%)$ and per vaginal route $(8.77 \%$ ) (Figure 5).

Antimicrobials were mostly prescribed from FDA Category B (96\%), followed by $2 \%$ each from FDA Category $\mathrm{C}$ and D (Figure 6).

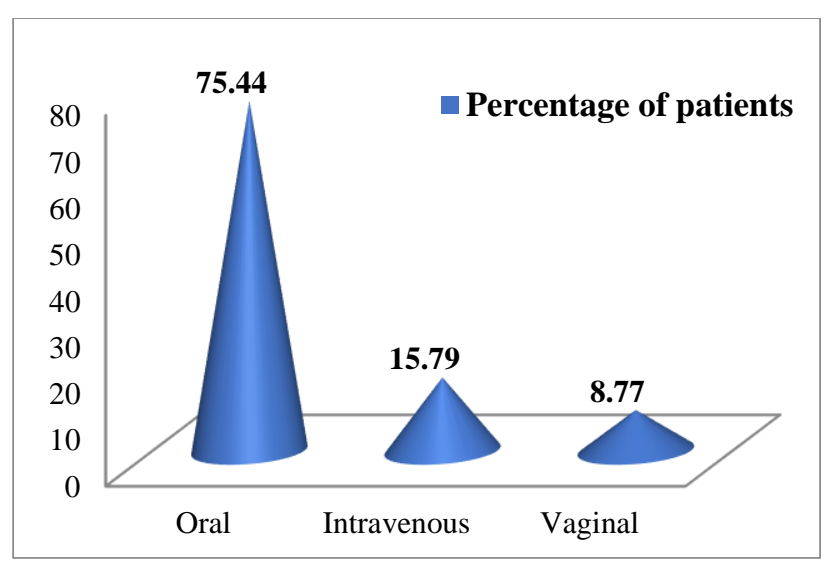

Figure 5: Route of administration.

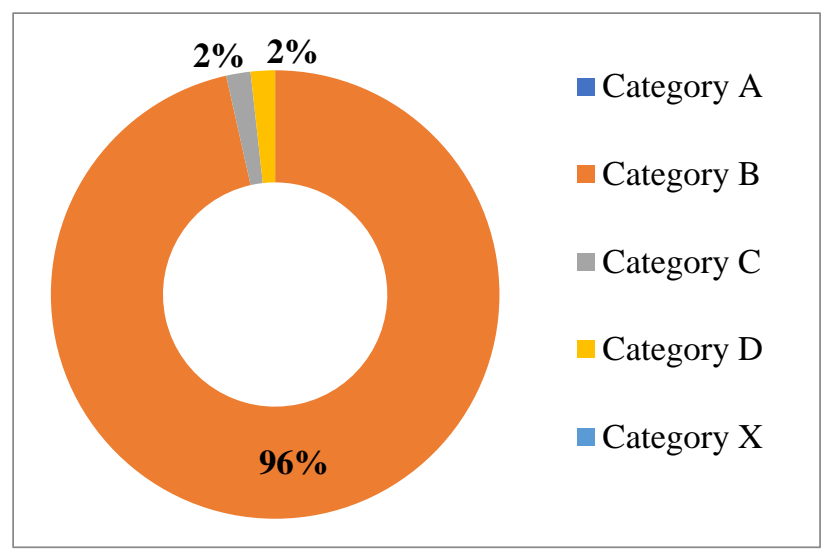

Figure 6: FDA category of antibiotics prescribed.

\section{DISCUSSION}

The most prevalent infections during pregnancy were RTIs; however, most of them were treated symptomatically.

A little more than one-third of the conditions encountered were UTIs, which were the leading cause for antimicrobial treatment. A similar finding was reported in the studies done in South India and Africa. ${ }^{11,12}$ It is a known fact that gravid uterus exerts pressure over urinary bladder resulting in retention of urine leading to UTIs. ${ }^{12-14}$

Betalactams constituted two-fifths of the antimicrobials prescribed followed by Nitrofuranes and Nitroimidazoles similar to the study reports from South India and Africa. ${ }^{11,12}$ In this study, among betalactams, Cephalosporins were the most commonly used antimicrobials. It is similar to the prescription pattern reported in Africa. ${ }^{11,12}$ In a study conducted in South India, Penicillins were the most common in contrast to our study. ${ }^{11}$

Antifungals prescription was observed in one-tenth of cases in this study, which is higher than that reported from a study in South India. ${ }^{11}$ 
The mean age of the participants in this study was similar to that reported in a study done in Nigeria. ${ }^{1,15}$

Multigravidae formed the majority of women attending the antenatal clinics as observed in other studies. ${ }^{11,12}$ About one-third of pregnant women included in this study had antimicrobial exposure. Two-thirds of them had antimicrobial exposure in the third trimester which is a similar finding to the study done in Africa. ${ }^{12}$ Increased incidence of urinary tract infections and gastroenteritis leads to increased antimicrobial exposure during third trimester. ${ }^{12,16,17}$

In three-fourths of the cases, antimicrobials were administered orally, the rest were administered parenterally and per vagina in this study. Oral route is commonly preferred over parenteral route to minimize toxicity during pregnancy. ${ }^{1}$

Almost all the antimicrobials used were from FDA category $\mathrm{B}$ and therefore considered to be safe in pregnancy. Results of our study are in concordance with the study done in Africa. ${ }^{12}$

There was one participant who had RTI and was treated with Clarithromycin, a macrolide belonging to FDA category C. Macrolides though safe, directly stimulate the motilin receptors inducing Gastro-intestinal discomfort which may be undesirable in pregnancy. ${ }^{12,18}$ Another participant had incomplete abortion for which Doxycycline (FDA category D) was prescribed. Overall, the antimicrobials usage in this study can be considered to be safe.

Most infectious conditions encountered were during $3^{\text {rd }}$ trimester of pregnancy, so majority of antimicrobials exposure occurred in this period. The duration of use was for 5-6 days. Two of the cases did not improve within this period and required $2^{\text {nd }}$ course of medication.

\section{CONCLUSION}

RTIs were the most common among the conditions encountered. However, UTIs were the leading cause for antimicrobials prescription. Antimicrobials prescription was more during $3^{\text {rd }}$ trimester. Majority of the antimicrobials were administered orally. Most antimicrobials prescribed were safe as they were from FDA Category B.

\section{Funding: No funding sources}

Conflict of interest: None declared

Ethical approval: The study was approved by the Institutional Ethics Committee

\section{REFERENCES}

1. Eze UI, Eferakeya AE, Oparah AC, Enato EF. Assessment of prescription profile of pregnant women visiting antenatal clinics. Pharmacy Practice (Internet). 2007 Sep;5(3):135-9.

2. Heikkilä AM. Antibiotics in Pregnancy A Prospective Cohort Study on the Policy of Antibiotic Prescription. Annals of Medicine. 1993 Jan 1;25(5):467-71.

3. Bookstaver PB, Bland CM, Griffin B, Stover KR, Eiland LS, McLaughlin M. A review of antibiotic use in pregnancy. Pharmacotherapy: The Journal of Human Pharmacology and Drug Therapy. 2015 Nov;35(11):1052-62.

4. Nahum GG, Uhl K, Kennedy DL. Antibiotic use in pregnancy and lactation: what is and is not known about teratogenic and toxic risks. Obste Gynecol. 2006 May 1;107(5):1120-38.

5. Andrade SE, Gurwitz JH, Davis RL, Chan KA, Finkelstein JA, Fortman K, et al. Prescription drug use in pregnancy. Am J Obstet Gynecol. 2004;191:398407.

6. de Tejada BM. Antibiotic Use and Misuse during Pregnancy and Delivery: Benefits and Risks; Int J Environ Res Public Health. 2014 Aug;11(8):9938009.

7. Costantine MM. Physiologic and pharmacokinetic changes in pregnancy. Front Pharmacol. 2014;65:1-5.

8. Young VS. Teratogenicity and Drugs in the breast milk. Applied Therapeutics: The Clinical Use of Drugs $7^{\text {th }}$ edition USA Lippincott Williams \& Wilkins; 2001.

9. Collabourative Group on Drug Use in Pregnancy. An international survey on drug utilization. Int J Risk Safety Med. 1991;1:1.

10. Babu RH, Basha KM, Kumar BS, Nagaraju R. A Study on Anti-microbial Prescribing Pattern during Pregnancy in a Tertiary care Hospital in South India. Int J Innov Pharma Res. 2010;1(1):11-3.

11. Mensah KB, Opoku-Agyeman K, Ansah C. Antibiotic use during pregnancy: a retrospective study of prescription patterns and birth outcomes at an antenatal clinic in rural Ghana. J Pharma Poli Practi. 2017 Dec;10(1):24.

12. Masinde A, Gumodoka B, Kilonzo A, Mshana SE. Prevalence of urinary tract infection among pregnant women at Bugando medical Centre, Mwanza,Tanzania. Tanzan J Health Res. 2009;11(3).

13. Köksal Ö, Özdemir F, Armağan E, Öner N, Sert PÇ, Sigirli D. Is routine pregnancy test necessary in women of reproductive age admitted to the emergency department World J Emerg Med. 2013;4(3):175.

14. Das B, Sarkar C, Datta A, Bohra S. A study of drug use during pregnancy in a Teaching Hospital in Western Nepal. Pharmacoepidemiol Drug Saf. 2003;12(3):221-5.

15. Mensah KB, Ansah C. Irrational use of antibiotics and the risk of diabetes in Ghana. Ghana Med J. 2016;50(2):107-14.

16. Prescott SL, Clifton V. Asthma and pregnancy: emerging evidence of epigenetic interactions in utero. Curr Opin Allergy Clin Immunol. 2009;1:9(5):417-26. 
17. Weber FH Jr, Richards RD, McCallum RW. Erythromycin: a motilin agonist and gastrointestinal prokinetic agent. Am J Gastroenterol. 1993;88(4):1.

18. Periti P, Mazzei T, Mini E, Novelli A. Adverse effects of macrolide antibacterials. Drug Saf. 1993;1:9(5):346-64.
Cite this article as: Begum MA, Sowmya BK, Shailendra D. Prescription pattern of antimicrobials in pregnant women attending antenatal clinic in a tertiary care hospital in Telangana, India. Int J Basic Clin Pharmacol 2019;8:176-80. 